УДК 574.4

\title{
ВИДОВОЙ СОСТАВ РАСТИТЕЛЬНЫХ СООБЩЕСТВ МАРЫЙСКОГО ВЕЛАЯТА ТУРКМЕНИСТАНА
}

\section{Бибалова Людмила Владимировна к.б.н., доцент}

\section{Абдылаев Арслан Бердымурадович}

ФГБОУ ВО «Адыгейский государственный университет»

Аннотация: сравнительный анализ и инвентаризация современного состояния видового разнообразия растительных сообществ Марыйского велаята в связи с высотно - горизонтальной структурой фитоценозов показал, что в горной части в пределах 500 - 1200 метров над уровнем моря, преобладают среди деревьев сумаховые - 9,5\%, кустарников гречишно гребенщиковые - 8,0 \% и травянистой растительности мятликово сложноцветные - 38,0\% ; на равнине в пределах 170 - 330 м н. у. м. ивовые $6,5 \%$, гребенщиково - гречишные - $13,0 \%$, мятликово - амарантовые - $41,0 \%$, и сложноцветно - бобовые - $15,0 \%$.

Ключевые слова: видовой состав, растительные сообщества, Бадхыз, Кушка, тугайные леса, Мургаб, высотно - горизонтальная структура.

\section{SPECIES COMPOSITION OF PLANT COMMUNITIES OF MARY VELAYAT OF TURKMENISTAN}

Bibalova Lyudmila Vladimirovna AbdylaevArslan Berdymuradovich

\begin{abstract}
: a comparative analysis and inventory of the current state of the species diversity of plant communities in the Mary province in connection with the altitudinal - horizontal structure of phytocenoses showed that in the mountainous part within 500 - 1200 meters above sea level, Empetraceae trees predominate 9,5\%, Polygonaceae - Tamaricaceae - shrubs - 8,0\% and herbaceous vegetation Poaceae - Asteraceae - 38,0\%; on the plain within $170-330 \mathrm{~m}$ above sea level Salicaceae - 6,5\%, Tamaricaceae - Polygonaceae - 13,0\%, Poaceae Amarantaceae - 41,0\%, and Asteraceae - Fabaceae - 15,0\%.

Key words: species composition, plant communities, Badkhyz, Kushka, riparian forests, Murgab, vertical - horizontal structure.
\end{abstract}




\section{ВСЕРОССИЙСКИЙ ИССЛЕДОВАТЕЛЬСКИЙ ФОРУМ СТУДЕНТОВ И УЧАЩИХСЯ}

Одной из самых засушливых зон Туркменистана , является Марыйский велаят, где наблюдается значительный рост деградационных процессов в природной среде и истощение земельных, водных, и биологических ресурсов, о чем свидетельствует расширение ареала процессов опустынивания.

В связи с этим существует особая необходимость в целенаправленной, системно организованной инвентаризации растительного покрова как основы комплексного изучения биосферы, базы для разработки научно обоснованных мероприятий по рациональному природопользованию и сохранению экосистем.

Цель исследования - определить видовой состав растительных сообществ в связи с высотно-горизонтальной структурой фитоценозов Марыйского велаята.

\section{Материал и методы исследования.}

Геоботанические описания растительности проводились общепринятыми методами. Общее проективное покрытие растений определяли по методике Л.Г. Раменского. Для оценки численного обилия особей отдельных видов в нашей работе использовалась шкала Друде. При оценке травянистой и кустарниковой растительности применили шкалу Браун - Бланке.[1;3;4;5]

Объектами исследования стали равнинные территории пустыни Каракумы, тугайные леса Мургаба, степи Бадхыза и горные экосистемы Карабиля, Бадхыза, Кушки.

Шесть экспериментальных площадок размером $5 \times 5$ м $\underline{2}$ были заложены на различных почвах велаята для геоботанических исследований в 2017- 2020 годах.

Пробная площадь №1 была заложена в междуречье Теджена и Мургаба на возвышенности Бадхыз, это Пулихатумская роща - крупный естественный массив фисташки в пределах распространения территории наших исследований от 337 м н.у.м.; (Рис. 1) 


\section{ВСЕРОССИЙСКИЙ ИССЛЕДОВАТЕЛЬСКИЙ ФОРУМ СТУДЕНТОВ И УЧАЩИХСЯ}

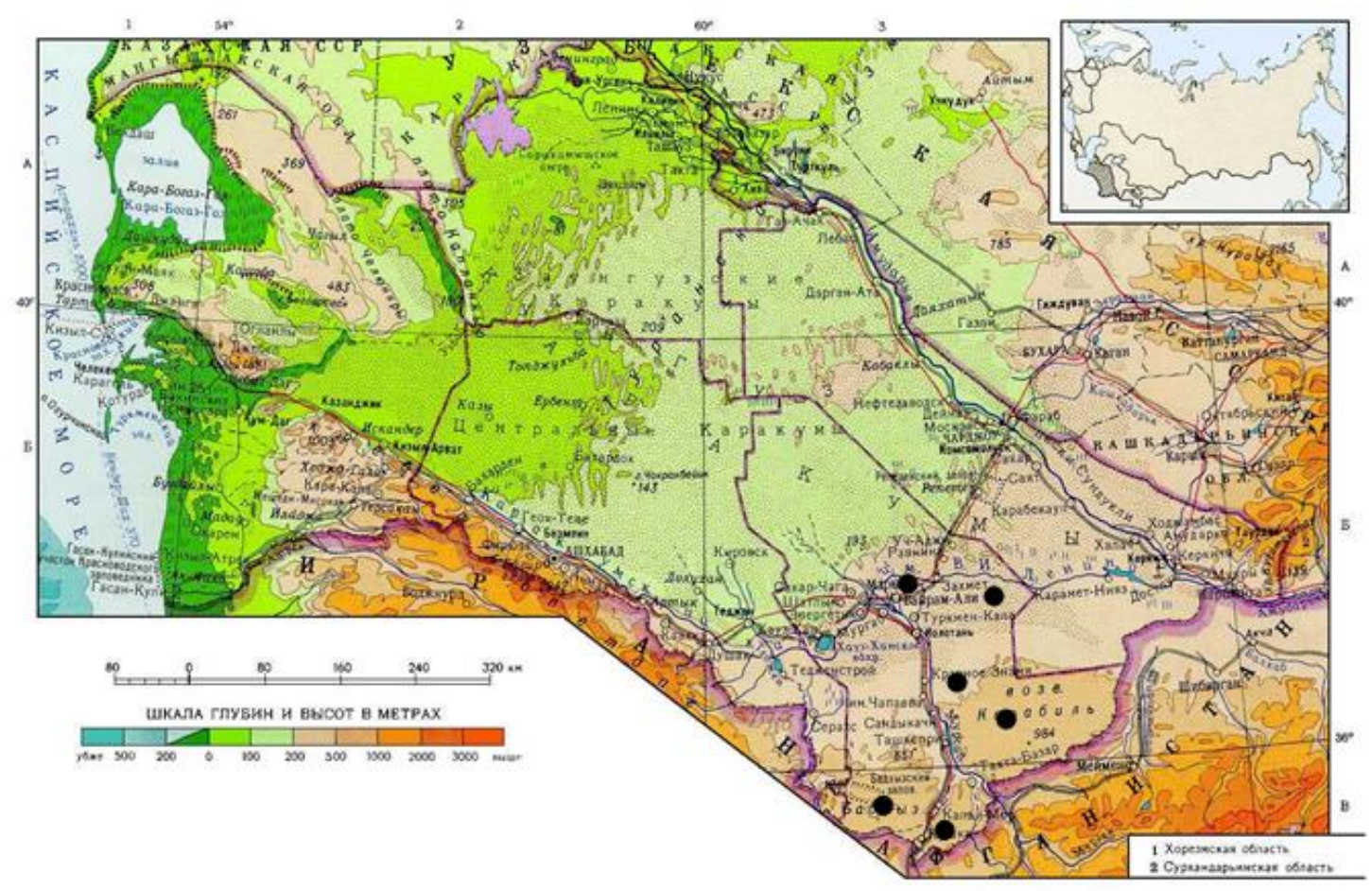

Рис.1. Карта Марыйского велаянта Туркменистана

Пробная площадь №2 - окрестностях Серхетабата на правом берегу реки Кушка на высоте 600 м н.у.м.;

Пробная площадь №3 - на возвышенности Карабиль - между Лекгером и Гарбангула на высоте 600 - 900 м н.у.м.;

Пробная площадь №4 - долине р. Мургаб между поселком Тахта - Базар и г. Иолотань (280 - 330 м);

Пробная площадь №5 - между п. Туркменкала, Байрам-Али и Каракумским каналом в юго-восточных каракумах на высоте 180-200 м н.у.м.;

Пробная площадь № 6 - в Мургабском оазисе - дельте р. Мургаб на высоте 170 - 280 м н.у.м.

При определении и уточнении видов растений использовались определители А.А. Гроссгейма и Б.А. Федченко [2;6;7]

\section{Результаты исследования и их обсуждение.}

Видовой состав растительных сообществ территории исследования включает более 130 видов растений, относящихся к 34 семействам.

Флористический состав пробных площадей № 4, № 5, № 6 равнинной территории велаята в долине реки Мургаб, Мургабском оазисе и в каракумах Байрам - Алийского этрапа включают: деревья - 13,0 \%, кустарники - 30,0\%, травы - 57,0 \%. Причем на площадке № 4 высокие травы занимают $-43,0 \%$, a 
низкие травы - 17,0\%. Из деревьев: Populus pruinosa и Populus euphratica O.всего 7 деревьев, Eleagnus orientalis - 3, Ulmus carpinifolia - 4, Salix acmophylla - 5, Paliurus spina-christi M., - 2, Morus nigra L. -3, Punica granatum - 2 и всего одна Ammodendron karelinii Fisch на участке № 5.

Из кустарников лидирует Tamarix ramosissima и Tamarix hispida - 15 растений, Calligonum aphyllum P. - 10, Haloxylon persicum - 9 и Alhági - 9. Особенно много кустарников на площадке № 5 - 32 растения и № $6-18$. Кустарниковую растительность мы представили гребенщиково - кандымовой и саксаулово - вербльюжей колючковой ассоциациями.

Из травянистой растительности на равнинной территории много злаков $33,0 \%$ и ивовых - 12,0\% на пробной площади № 4, амарантовые - 32,0\% и гребенщиковых 12,0\% на площадке № 5, сложноцветных - 13,0\% - на площадке № 6, и осоковых - 10,0 \% на № 4; № 5. Много сорной растительности - 12,0\%.

Итак , на равнине доминируют мятликовые - 29,0\%, амарантовые $12,0 \%$, бобовые - 8,0\%, гребенщиковые - 7,0\%, сложноцветные - 7,0\%, гречишные $-6,0 \%$, ивовые - 5,0\%. Остальные $26,0 \%$ распределились между 16 семействами, где каждая из них занимала - от 1,0 до 3,0 \%. (Рис.2)

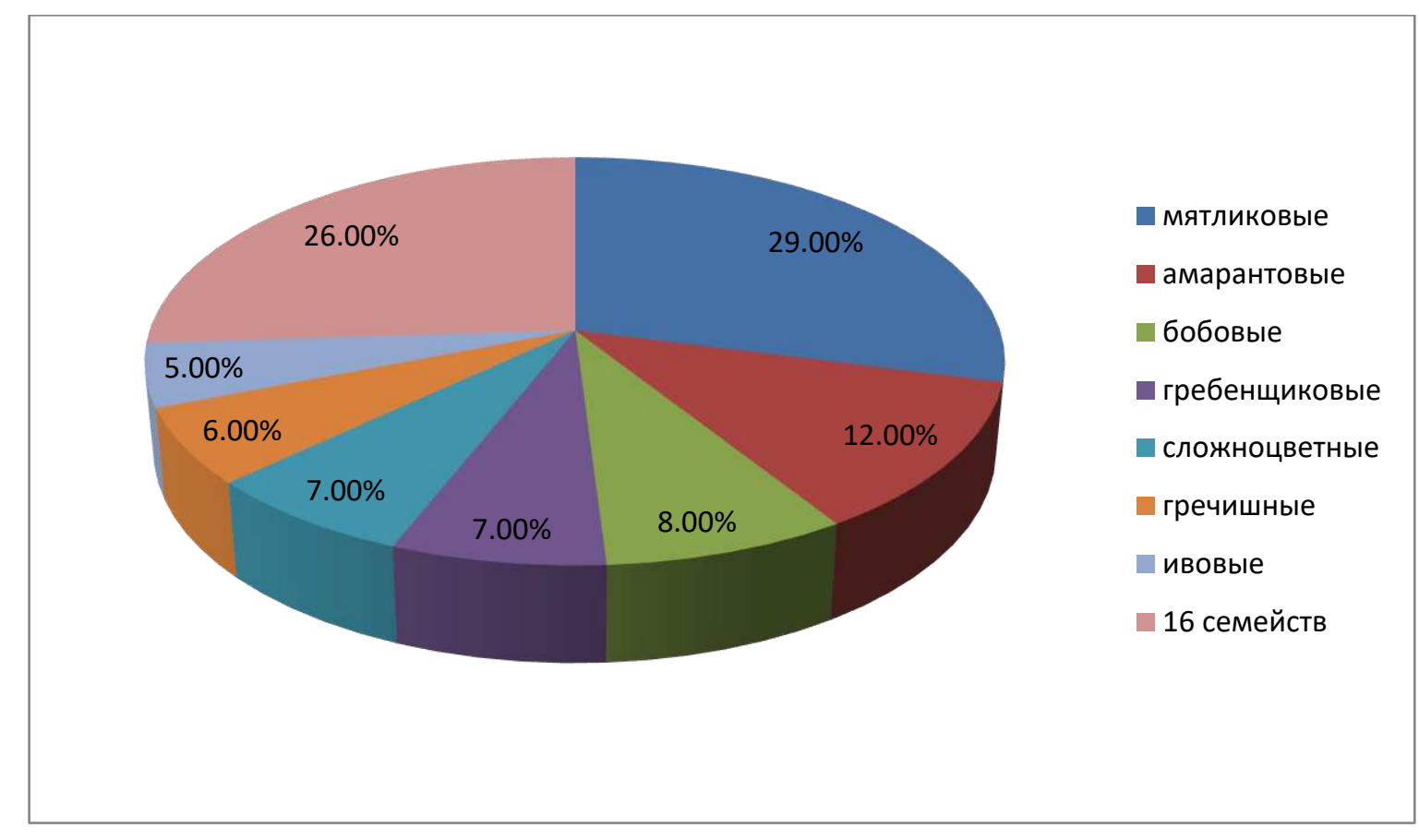

Рис. 2. Флористический состав на равнинной территории Марыйского велаята 
Анализ исследуемых площадок № 1, № 2, № 3, находящиеся на территории горных экосистем велаята показал, что на долю деревьев приходится - 15,0 \%, кустарников - 10,0\% и 15,0\% - высокие травы, и 60\% - низкие травы. Причем Pistacia badghysi занимает - 9,5 \%, кустарники Tamarix ramosissima и Calligonum aphyllum - 4,0 \% .

На Бадхызе и Кушке фисташки находятся на расстоянии друг от друга, а под ними кустарники Lonicera persica и все это на протяжении всего заповедника от 600 м до 1200 м н.у.м. и внизу на высоте 300 - 400 м н.у.м. злаково - разнотравная растительность с вкрапленными яркими Papaver hybridum L. и Tulipa kushkinskaya, T.Lehmanniana. Здесь много редких и эндемичных видов - 30,0 \% .

Почти рядом на правом берегу Мургаба, горы Карабиля обладают скудной растительностью - много сорной и представителей мятликовых и осочковых растений - $60 \%$.

В горной части велаята мятликовые занимают - 22,0\% ,сложноцветные $16,0 \%$, сумаховые - 9,5\%, крестоцветные - $5.5 \%$, гречишные - 4,0\% амарантовые - 3,0\% и 40,0\% принадлежат представителям 17 семейств, на каждую из которых приходится от 1,0 до 3,0 \%. (Рис.3)

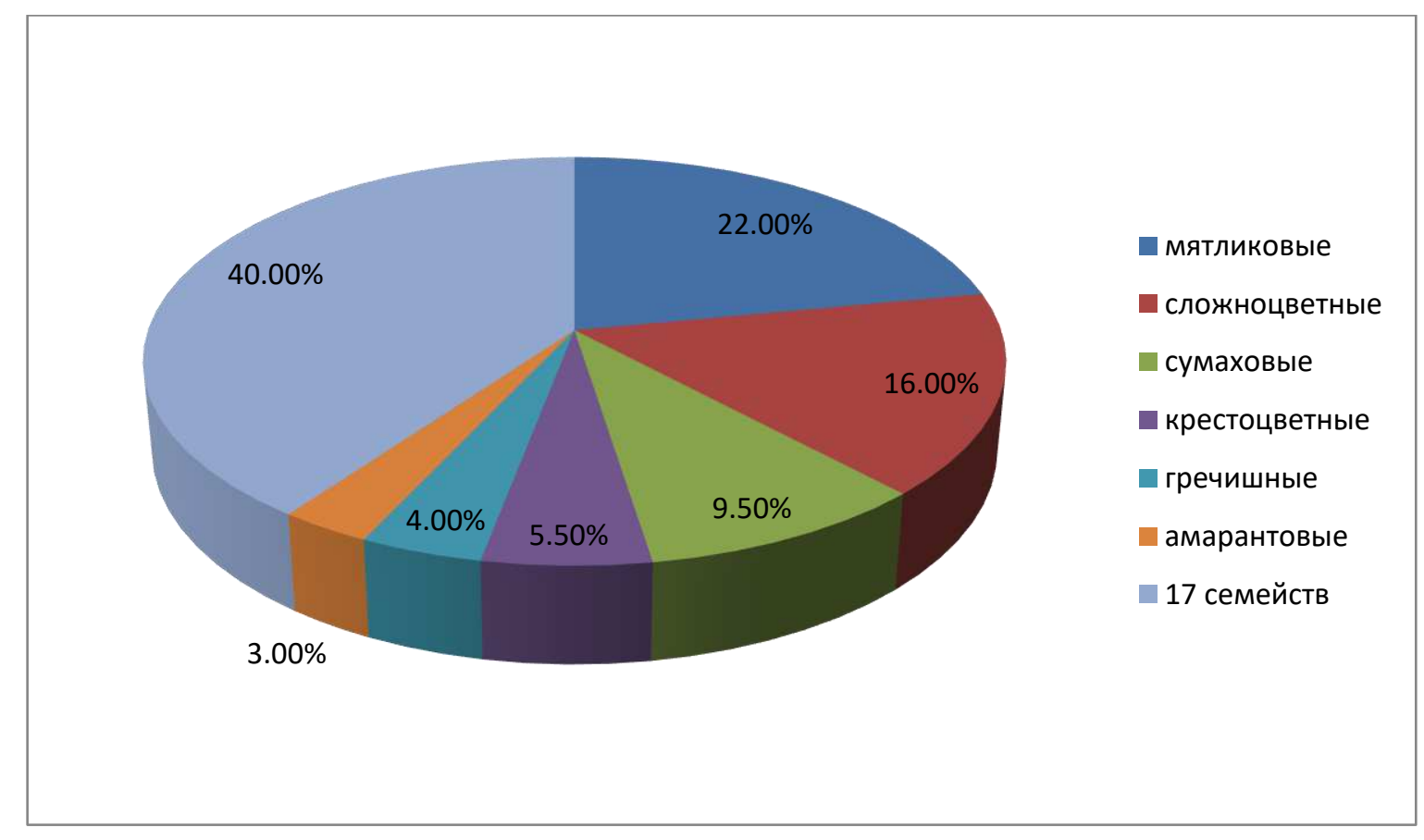

Рис. 3. Флористический состав на территории горных экосистем Марыйского велаята 
Сравнительный анализ растительных сообществ на пробных площадях равнинной и горной исследуемой территории Марыйского велаята показал ,что преобладают мятликовые - 29,0\% на равнине и $22,0 \%$ в горной части, сложноцветные $-7,0 \%$ и соответственно - $16,0 \%$, амарантовые $-12,0 \%$ и $3,0 \%$, и гречишные - 6,0\% и 4,0\%.(Рис. 4)

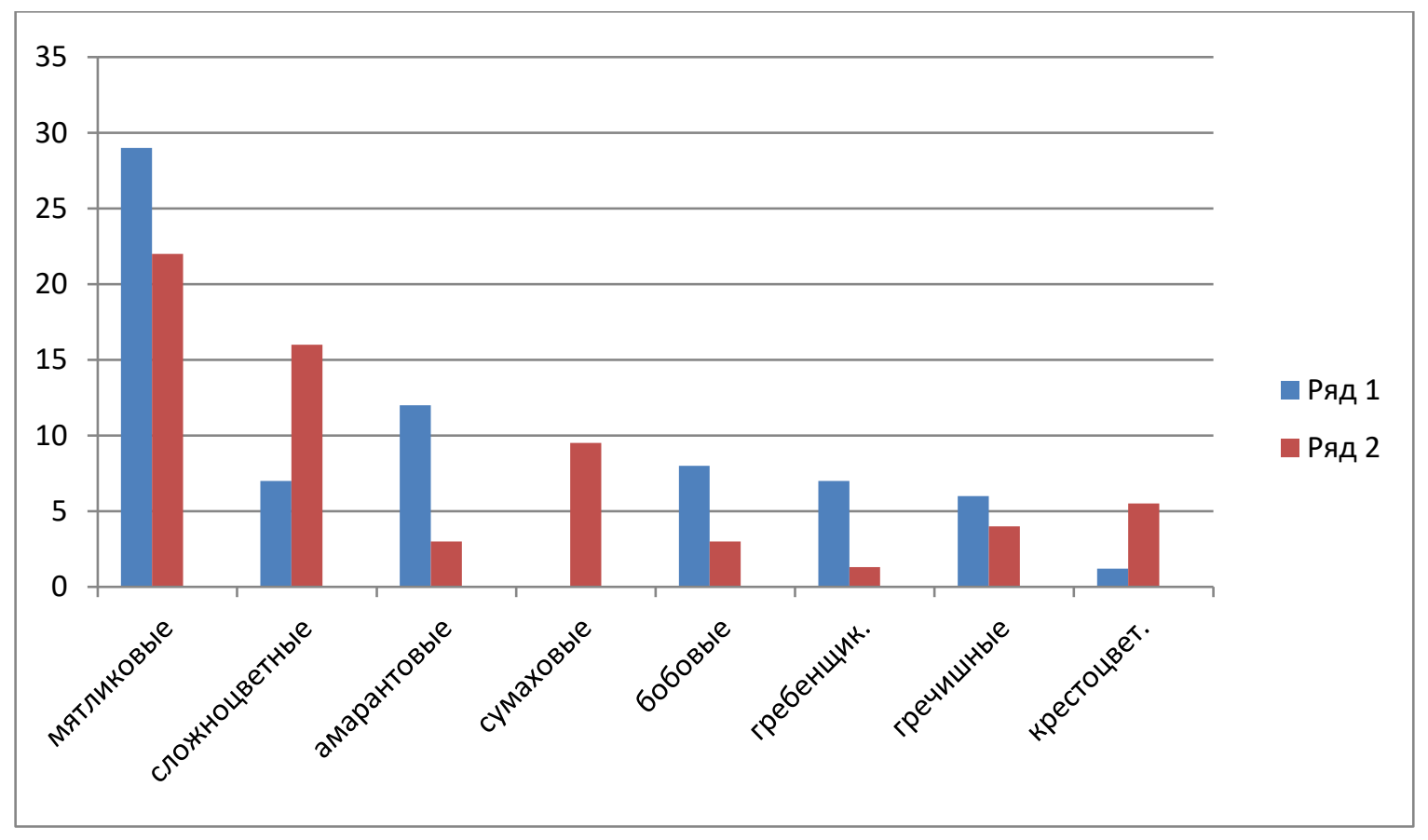

Рис. 4. Сравнительный анализ растительных сообществ на равнинной и горной территории Марыйского велаята

В горах сумаховые занимают - 9,5\%, а на равнине их нет. Гребенщиковые на равнине $-7,0 \%$ и на высотах $-1,5 \%$, бобовые $-8,0 \%$ и соответственно $-3,0 \%$.

Итак, в горной части преобладают среди деревьев сумаховые - 9,5\%, кустарников гречишно - гребенщиковые - 8,0 \% и травянистой растительности мятликово - сложноцветные - 38,0\%. На равнине ивовые, гребенщиково гречишные - $13,0 \%$ и мятликово - амарантовые $-41,0 \%$, и сложноцветно бобовые $-15,0 \%$.

Растительные сообщества в связи с высотно - горизонтальной структурой фитоценозов обитают на равнинной территории в пределах $170-330$ метров над уровнем моря от Мерва, Мургабского оазиса, каракумах Байрам-Алийского этрапа, г. Иолотань и поселка Тахта-Базар. 


\section{ВСЕРОССИЙСКИЙ ИССЛЕДОВАТЕЛЬСКИЙ ФОРУМ СТУДЕНТОВ И УЧАЩИХСЯ}

Растительные сообщества в связи с высотно - горизонтальной структурой фитоценозов горных экосистем велаята обитают в пределах 500 - 1200 метров над уровнем моря от Сандыкачи, Карабиля, до Серхетабада, Кушки и верховий Бадхыза.

\section{Выводы:}

1. Во флоре исследуемой территории Марыйского велаята зарегистрировано 130 видов растений, относящихся к 34 семействам; к аборигенной флоре отнесено 100 видов (75,2 \%), к адвентивной - 30 вида (24,8\%).

2. В таксономической структуре аборигенной флоры ведущую роль играют семейства: Asteraceae, Poaceae, Empetraceae, Fabaceae, Polygonaceae, Amarantaceae.

3. В связи с высотно - горизонтальной структурой фитоценозов в Марыйском велаяте мы выделили:

- Растительные сообщества экосистемы пустыни и искусственных оазисов в пределах 170 - 600 метров над уровнем моря.

- Растительные сообщества экосистемы тугайных лесов в пределах от 300 до 500 м н.у.м.

- Растительные сообщества экосистемы степи от 320 м до 400 м н.у.м.

- Растительные сообщества экосистемы фисташковых лесов от 600 - 1200 M H.y.M.

- Растительные сообщества экосистемы высокогорий в пределах 900 1200 и н.у.м.

\section{Список литературы}

1. Быков Б.А. Геоботаника.-АН Казахской ССР.-Алма-Ата,1957.-382c.

2. Гроссгейм А.А. Анализ флоры Кавказа //Труды ботанического института АНСССР.-Баку,1936.-Том1.-260с.

3. Миркин Б.М. Современное состояние и тенденции развития классификации растительности методом Браун-Бланке //Итоги науки и техники ВИНИТИ.- Сер. Ботаника, 1989.- №9. - С. 1-128.

4. Раменский Л.Г. Экологическая оценка кормовых угодий по растительному покрову.-М.:Сельхозгиз,1956.-472c.

5. Шенников А.П. Введение в геоботанику.-Л.:Изд-во ЛУ,1964.-447с.

6. Федченко Б.А. Растительность Туркестана .- Петроград, 1915.- 824 с.

7. Флора Туркмении / Под общ. ред. проф. Б. А. Федченко .- Туркмен. ботан. сад НКЗ ТССР. - Ашхабад.- Туркменгосиздат, 1948-1960. - 5т. - 250 с.

(C) Л.В. Бибалова, А.Б. Абдылаев, 2020 